\title{
The Upstream Linkage of HRM Practices with Job Performance; and Surrogating Role of Perceived Employee Development
}

\author{
Shahid Iqbal \\ M.Phil Scholar, \\ College of Commerce, GC University Faisalabad \\ Muhammad Moazzam Shahzad \\ M.Phil Scholar, \\ College of Commerce, GC University Faisalabad
}

\begin{abstract}
The study has strived to enlighten the relationship of HRM Practices with employee development and job performance, sample was taken from 235 SMES of Punjab, Pakistan. A total of 784 white collar employees participated in the survey from which 64 responses were not found fit to be analyzed due to missing values; from 720 responses 12 responded were further eliminated due to outliers and abbrent values. The total 708 responses were analyzed through MPlus Software.
\end{abstract}

DOI: $10.7176 / \mathrm{JRDM} / 53-01$

Publication date:March $31^{\text {st }} 2019$

\section{Introduction}

Studies related to the employees' belief that their work organization values, their contribution and cares about their well beings and perceived organizational support. The archive shows that the employees' can get three types of benefits fairness, supervisory support and organizational reward and favorable job conditions. These are associated with the career success. In return of perceived employee development relates to the positive and favorable outcomes to the employees associated with Job satisfaction, Positive mode and the organization Affective Commitment, Performance and reduced withdrawal behavior (Khan, Khulida, \& Tan, 2014).

Employees which are highly committed with the organizations they shows intensive performance reduced absenteeism and a less likelihood of quitting their job. Being valued by the organization can get following benefits as approval and respect pay and promotion, and access to information and other forms of support needed to better carry out once job. When one person treats another well then in exchange the favorable treatment becomes obvious. When both the employee and employer apply the exchange of norms to their relationship favorable treatment received from the both sides (Arthur, Khapova, \& Wilderom, 2005).

However, Organization Support Theory: According to the organizational support theory the development of POS is supported by employees, tendency to assign the organization human link characteristics on the basics of organization picture employees viewed their favorable or unfavorable treatment as a given hint or manifestation that the organization favors or disfavors them (Zafar, Bashir, Abrar, \& Ghazanfar, 2014).

Whereas, Social Exchange Theories: This theory explained that all Types of Resources which received from other are more valued able. If they are based on optional choice or personal choice rather than circumstances beyond the donors' control. Such voluntary behaviors are welcomed as an indication that the donor genuinely values and respect the recipients (Saher, Bibi, Farmanullah, \& Abbas, 2014). Thus, All the rewards which received from the organization are more auspicious, While the condition of the job like as progress in the job rank, upgrading of the job, effect on the overall policies of the organization all these strengthen to the perceived organizational support. If the employees believe that they result from the organizations voluntary action as implemented to the outsiders like as the union dialogues and orders or government health and safety rules and regulations are implemented (Zafar et al., 2014).

Whereas, All the important and interesting features of the organizational support theory provides clear accurate rapidly testable predications and outcomes of the perceived Employee development (PED), along with specifying of assumed processes and ease of testing these processes empirically.

Meta analysis showed aggregate concerning to proposed antecedents and consequences of PED. Firstly we extracted hypothesized antecedents and consequences from approximately one third of the PED studies have established a preliminary set of categories. We reviewed the remaining studies and made adjustments to the categories through discussion. We described these categories discussed their theorized relationships with PED delineate the meta analysis procedures and then present our findings. After correcting the effect size for sampling error and measurement error we use path analysis to compare the relative strengths of the relationships between PED and the HRM Practices with Job Performance (Mwamila \& Diyamett, 2009).

According to the lights of the organizational support theory there are three general forms of the perceived favorable treatment which received from the organization: 
(1) Fairness,

(2) Supervisor Support

(3) Organizational Rewards and

(4) Job Conditions should increase PED.

Fairness: Equal distribution of resources towards the employees of the organization is known as fairness that is deal in procedural justice. Whilst, to attain a strong PED from the employees of the organization, it is necessary that repeatedly exampled of fairness in the decision making used. There is a difference between social and structural views of procedural justice (Shanmugam, 2016; van Dierendonck \& van der Gaast, 2013).

Structural justice includes rules, regulations, policies and standards relating to the decisions that may affect the employees where as Social view of procedural justice included behave the employees in allocation of resources, dignity and true respect is given to employees.

Supervisory Support: supervisor is like the agent of the organization with responsibility to guide the subordinates and access their performance. Employees evaluate their supervisor as favorable or unfavorable for them. Supervisor's support is evaluated with relating to measures leader-member exchange (L M E) with each other (Chung, Rutherford, \& Park, 2012).

A large number of rewards and job conditions is concerned to POS have positive effect for instance salary, job autonomy, security, training, and development. Personality has positive influence on PED through employee behavior. However, there are some dispositional variables that have positive or negative effect relating to two different personality dimensions (Linz, 2003; Shanmugam, 2016).

Demographic characteristics are commonly used as control variable to express the different views that are related to POS and antecedents. These features are gender, experience, education, and age

\section{Literature Review:}

Overall human resource management is very important for the success of any organization.Organization can not perform very well without the human resource management system.no body can deny the importance of human resource management (Fox, Spector, \& Miles, 2001). All the researchers are agreed at this point that that firms can get competitive advantages to improve the human resource management system.it is the key of success, and it is the excilusive source to get the competitive advantage if the organization fulfills the following four basics requirements;(1)the performance of the individual person add the value to the out put of the organization,it means the the individual performance plays an important role in the value of the organizations output.(2)extraordinary individual skills are required. (3)they are demanded not to copied with easy way,not replicate.(4)advance technology is not the substitute for them.In the human resource management the performance appraisal plays a very important role and its prosess is very important.its effects is on both financial and program components of any organization.it is helpful for the employees and for the organizations for achieving their goals (Gutteridge, 1973; Safdar, 2012).

It empowered the employees that they can explain their progress to achieveing the goals towards the organizational or personal goals.All the researchers define the performance appraisal in sence of their role and place in the organization.Basically it is a structured and formal interaction between the appraise and the appraiser ,as a periodic interview which focus on the job performance of the appraises and its main purpose is to check out the strengths, weaknesses and the opportunities for the purpose of improving skills and developments.it is mechanisum to check the skills of the individuals and to assign the values to improve their performance (Gunz, Mayrhofer, \& Tolbert, 2011; Jaskolka, Beyer, \& Trice, 1985).

Performance appraisal is a vital and more accepted strategy which is used in the organizations and is more successful for the organizations. This activity is necessary because to judgement the work of the other peoples is an human building theory. However this theory neither correct, acceptable or not.Every person has its own openion therefore it is not $100 \%$ sure that this theory is correct and acceptable.we can said that this human making system has a long historyof mixed reactions.some researchers said that the developing such appraisal system which is successful and effective in evaluating an employee's performance and accounting for his/her contribution in organization and also meets the organizational context requirements is an arduous and uphill task.

\section{Methodology:}

First we carried out a computer search of the Psycinfo and dissertation abstracts international database started with the introduction of the PED construct from 1986. We search out all the published and unpublished Articles and the thesis they used terms Perceived organizational Support, organizational support, or Perceived Support in the Title or in the Abstract. Secondly, we Search out all the web sites of sciences citation index for all tose Articles which referenced two major sources of Articles on PED. Thirdly we collect all the relevant Material which was unpublished, and Researchers provide us by investigating the PED. At the end we studied the lists of reference of all research reports which is used in the literature.

A self-administered closed ended questionnaire technique has been applied total no. of items 22 were included. 
The questionnaire consist of five point likert scale. Strongly disagree to strongly agree 1 to 5 . The questionnaire was adopted from Khan et. al (2010).

\section{Research Diagram:}

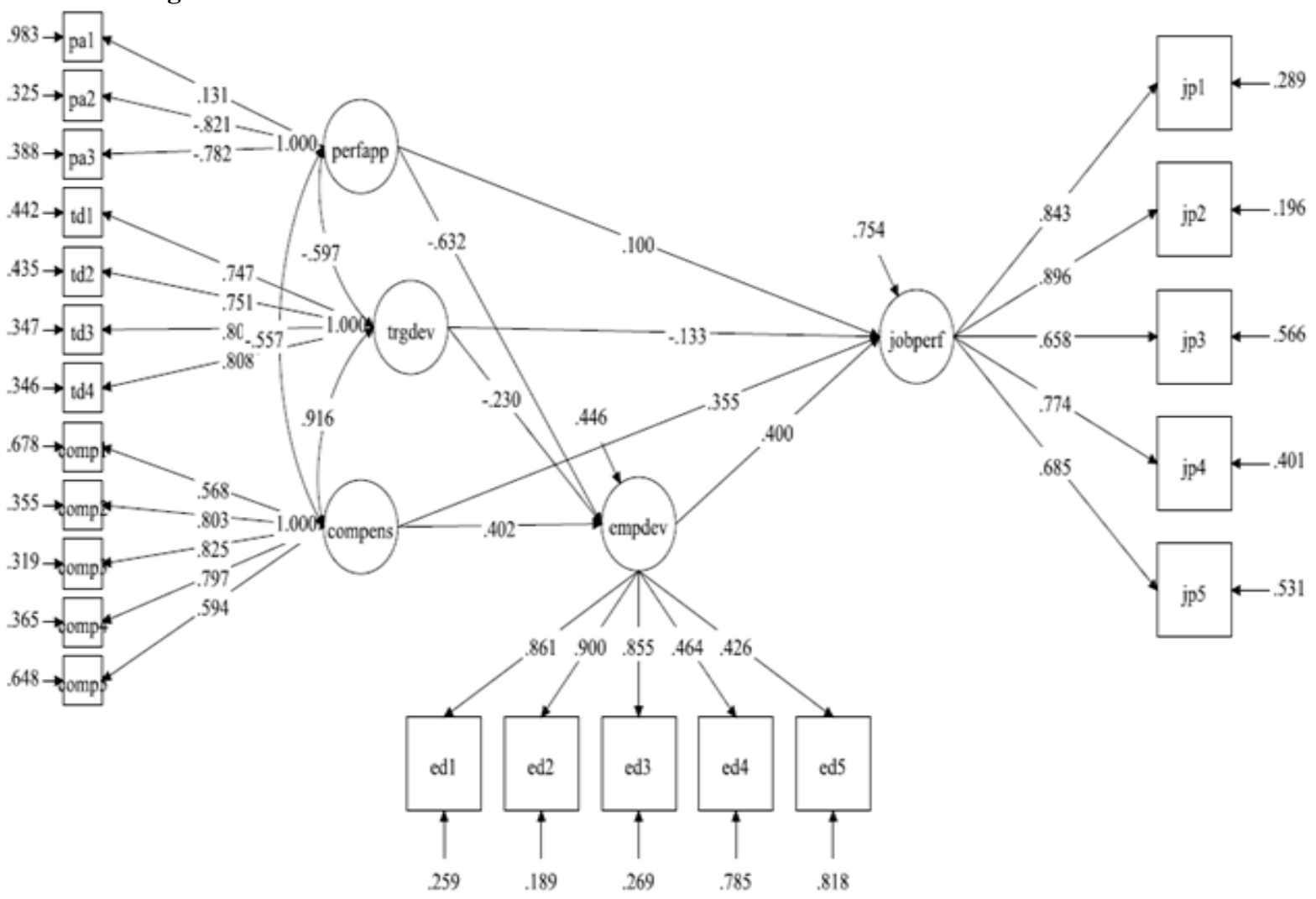

Results and Discussion:

Analysis:

Information Criteria:
Akaike (AIC):
Bayesian (BIC):
13035.342
Sample-Size Adjusted BIC:
13058.969

Chi-Square Test of Model Fit:

Value

Degrees of Freedom

P-Value

0.0000

RMSEA (Root Mean Square Error of Approximation):

Estimate

90\% (Percent C.I.)

Probability RMSEA

0.09

$$
\begin{aligned}
& 0.0900 .107 \\
& <=.05 \quad 0.000
\end{aligned}
$$

Comparatively Fit Index and Tucker-Lewis Index (CFI/TLI):

$\begin{array}{ll}\text { CFI } & 0.852 \\ \text { TLI } & 0.829\end{array}$

SRMR (Standardized Root Mean Square Residual):

Value:

0.116 
MODEL RESULTS:

Performance Appraisal is BY:

\begin{tabular}{lllll}
\hline & Estimate & Standard Error & T-Statistics & P-Value \\
\hline PA1 & 1.000 & 0.000 & 999.000 & 999.000 \\
PA2 & -6.733 & 4.671 & -1.442 & 0.149 \\
PA3 & -6.461 & 4.449 & -1.452 & 0.146 \\
\hline
\end{tabular}

Jon Performance BY

\begin{tabular}{lcccc}
\hline & Estimate & Standard Error & T-Statistics & P-Value \\
\hline JP1 & 1.000 & 0.000 & 999.000 & 999.000 \\
JP2 & 0.977 & 0.061 & 16.065 & 0.000 \\
JP3 & 0.764 & 0.074 & 10.358 & 0.000 \\
JP4 & 0.870 & 0.088 & 9.936 & 0.000 \\
JP5 & 0.755 & 0.097 & 7.824 & 0.000 \\
\hline
\end{tabular}

Employee Development BY:

\begin{tabular}{lllll} 
& Estimate & Standard Error & T-Statistics & P-Value \\
ED1 & 1.000 & 0.000 & 999.000 & 999.000 \\
ED2 & 1.146 & 0.055 & 20.768 & 0.000 \\
ED3 & 1.090 & 0.077 & 14.228 & 0.000 \\
ED4 & 0.693 & 0.132 & 5.231 & 0.000 \\
ED5 & 0.621 & 0.128 & 4.845 & 0.000 \\
\hline
\end{tabular}

Training and Development BY

\begin{tabular}{lllll}
\hline & Estimate & Standard Error & T-Statistics & P-Value \\
\hline TD1 & 1.000 & 0.000 & 999.000 & 999.000 \\
TD2 & 1.119 & 0.085 & 13.215 & 0.000 \\
TD3 & 1.190 & 0.108 & 10.979 & 0.000 \\
TD4 & 0.989 & 0.097 & 10.202 & 0.000 \\
\hline
\end{tabular}

COMPENS BY

\begin{tabular}{lllll}
\hline & Estimate & Standard Error & T-Statistics & P-Value \\
\hline COMP1 & 1.000 & 0.000 & 999.000 & 999.000 \\
COMP2 & 1.392 & 0.191 & 7.308 & 0.000 \\
COMP3 & 1.511 & 0.206 & 7.344 & 0.000 \\
COMP4 & 1.666 & 0.245 & 6.799 & 0.000 \\
COMP5 & 1.261 & 0.230 & 5.487 & 0.000 \\
\hline
\end{tabular}

JOBPERF ON

\begin{tabular}{lllll}
\hline & Estimate & Standard Error & T-Statistics & P-Value \\
\hline EMPDEV & 0.438 & 0.181 & 2.422 & 0.015 \\
PERFAPP & 0.784 & 1.816 & 0.432 & 0.666 \\
TRGDEV & -0.146 & 0.446 & -0.329 & 0.742 \\
COMPENS & 0.511 & 0.580 & 0.881 & 0.379 \\
\hline
\end{tabular}

EMPDEV ON

\begin{tabular}{lllll}
\hline & Estimate & Standard Error & T-Statistics & P-Value \\
\hline PERFAPP & -4.543 & 3.110 & -1.461 & 0.144 \\
TRGDEV & -0.231 & 0.298 & -0.775 & 0.438 \\
COMPENS & 0.527 & 0.397 & 1.328 & 0.184 \\
\hline
\end{tabular}

Path Coefficient:

\begin{tabular}{ll}
\hline Latent Variable & Estimate \\
\hline JOBPERF & 0.246 \\
EMPDEV & 0.554 \\
\hline
\end{tabular}


TOTAL, TOTAL INDIRECT, SPECIFIC INDIRECT, AND DIRECT EFFECTS:

Effects from EMPDEV to JOBPERF

\begin{tabular}{lllll}
\hline & Estimate & Standard Error & T-Statistics & P-Value \\
\hline Total & 0.438 & 0.181 & 2.422 & 0.015 \\
Total indirect & 0.000 & 0.000 & 0.000 & 1.000 \\
\hline
\end{tabular}

Direct JOBPERF

\begin{tabular}{lllll}
\hline & Estimate & Standard Error & T-Statistics & P-Value \\
\hline EMPDEV & 0.438 & 0.181 & 2.422 & 0.015 \\
\hline
\end{tabular}

STANDARDIZED TOTAL, TOTAL INDIRECT, SPECIFIC INDIRECT, AND DIRECT EFFECTS

STDYX Standardization

Effects from EMPDEV to JOBPERF

\begin{tabular}{lllll}
\hline & Estimate & Standard Error & T-Statistics & P-Value \\
\hline Total & 0.400 & 0.157 & 2.549 & 0.011 \\
Total indirect & 0.000 & 0.000 & 0.000 & 1.000 \\
\hline
\end{tabular}

Direct

JOBPERF

\begin{tabular}{lllll}
\hline & Estimate & Standard Error & T-Statistics & P-Value \\
\hline EMPDEV & 0.400 & 0.157 & 2.549 & 0.011 \\
\hline
\end{tabular}

STDY Standardization

Effects from EMPDEV to JOBPERF

\begin{tabular}{lllll}
\hline & Estimate & Standard Error & T-Statistics & P-Value \\
\hline Total & 0.400 & 0.165 & 2.422 & 0.015 \\
Total indirect & 0.000 & 0.000 & 0.000 & 1.000 \\
\hline
\end{tabular}

Direct

JOBPERF

\begin{tabular}{lllll}
\hline & Estimate & Standard Error & T-Statistics & P-Value \\
\hline EMPDEV & 0.400 & 0.165 & 2.422 & 0.015 \\
\hline
\end{tabular}

STD Standardization

Effects from EMPDEV to JOBPERF

\begin{tabular}{lllcl}
\hline & Estimate & Standard Error & T-Statistics & P-Value \\
\hline Total & 0.400 & 0.157 & 2.549 & 0.011 \\
Total indirect & 0.000 & 0.000 & 0.000 & 1.000 \\
\hline
\end{tabular}

Discussion and Future Recommendations:

The findings show the positively significant relationship of HRM practices with perceived Job performance, whereas, the perceived employee development has also been found significant with perceived job performance. Nevertheless, performance, compensation, training and development has not been found significantly positive with the perceived employee development.

Future researchers are advised to explore the construct by introducing further new variables. There are certain limitations associated with the study, such as scarcity of time and available limited financial sources. The study has included only skill enhancing HRM practices, new researchers are advised to include set of motivation enhancing HRM activities.

\section{References}

Arthur, M. B., Khapova, S. N., \& Wilderom, C. P. M. (2005). Career success in a boundaryless career world. Journal of Organizational Behavior, 26, 177-202.

Authors, F. (2015). Employee Relations : The International Journal. https://doi.org/10.1108/ER-08-2016-0167

Chung, T. L., Rutherford, B., \& Park, J. (2012). Understanding multifaceted job satisfaction of retail employees. International Journal of Retail and Distribution Management, 40(9), 699-716. https://doi.org/10.1108/09590551211255974

Fox, S., Spector, P. E., \& Miles, D. (2001). Counterproductive Work Behavior (CWB) in Response to Job Stressors 
and Organizational Justice: Some Mediator and Moderator Tests for Autonomy and Emotions. Journal of Vocational Behavior, 59(3), 291-309. https://doi.org/10.1006/jvbe.2001.1803

Gunz, H., Mayrhofer, W., \& Tolbert, P. S. (2011). Introduction to Special Section : Careers in Context Introduction to Special Section : Careers in Context.

Gutteridge, T. G. (1973). Predicting Career Success of Graduate Business School Alumni '. Academy of Management Journal, 16(1), 129-137.

Jaskolka, G., Beyer, J. M., \& Trice, H. M. (1985). Measuring and predicting managerial success. Journal of Vocational Behavior, 26(2), 189-205. https://doi.org/10.1016/0001-8791(85)90018-1

Khan, Q. I., Khulida, K. Y., \& Tan, F. Y. (2014). The Effects of Human Capital , Reward System and Career Commitment on Career Success and Mediating role of Counterproductive Work Behavior in Higher Education Sector of Pakistan . In 7th National Human Resource Management Conference 2014 (pp. 14-20). Alore Setar, Kedah D.A. Malaysia: Universiti Utara Malaysia.

Linz, S. J. (2003). Job satisfaction among Russian workers. International Journal of Manpower (Vol. 24). https://doi.org/10.1108/01437720310496139

Mwamila, B. L. M., \& Diyamett, B. D. (2009). Universities and socio-economic development in Tanzania: Public perceptions and realities on the ground. Science and Public Policy, 36, 85-90. Retrieved from http://www.scopus.com/inward/record.url?eid=2-s2.067649425393\&partnerID=40\&md5=2e82fa015af4168b4bfb1cc72643862d

Safdar, R. (2012). PERFORMANCE MEASUREMENT AND CIVIL SERVICES REFORMS IN PAKISTAN : A STUDY OF PUBLIC SECTOR ORGANIZATIONS. Far East Research Centre, 6(3), 56-68.

Saher, N., Bibi, S., Farmanullah, S. and, \& Abbas, S. (2014). Career Success in Pakistan: Human Capital and Social Networking. Middle East Journal of Scientifc Research, 19(2), $163-171$. https://doi.org/10.5829/idosi.mejsr.2014.19.2.2203

Shanmugam, M. M. (2016). Gender in Management : An International Journal Impact of Parenthood on Women ' s Career in the IT Sector - A Case Study in the Indian Context. Gender in Management: An International Journal, 32(5), 352-368. https://doi.org/10.1108/GM-11-2016-0177

van Dierendonck, D., \& van der Gaast, E. (2013). Goal orientation, academic competences and early career success. Career Development International, 18(7), 694-711. https://doi.org/10.1108/CDI-01-2013-0003

Zafar, S. S., Bashir, M., Abrar, M., \& Ghazanfar, F. (2014). Examining the Mediating Role of Employee Career Development in the Relationship between Learning Organization and Organizational Performance. International Journal of Business and Behavioral Sciences, 4(6), 55-69. 